\title{
Investigation into the Effects of Eight Weeks of Step Aerobic Dance Practice on Static Balance, Flexibility and Selected Basketball Skills in Young Basketball Players
}

\author{
Özhan Bavlı \\ Correspondence: Özhan Bavl, School of Physical Education, Çanakkale Onsekiz Mart University, Çanakkale, Turkey
}

Received: April 2, 2016 Accepted: April 12, $2016 \quad$ Online Published: April 15, 2016

doi:10.11114/jets.v4i5.1516 URL: http://dx.doi.org/10.11114/jets.v4i5.1516

\begin{abstract}
The aim of this study was to investigate the effects of eight weeks of step aerobic exercises on static balance, flexibility and selected basketball skills in young basketball players. A total of 20 basketball players (average age 16.1 \pm 0.7 years and average sporting age $4.1 \pm 0.7$ years) voluntarily joined the study. Participants were randomly divided into two groups (experiment n:10 and control n:10). All participants attended basketball training 3 days per week but the experiment group also had step aerobic dance practice 2 days per week. Before and after the study static balance, flexibility and selected basketball techniques were evaluated. SPSS statistical program used for analysis. Repeated measures Anova was used to compare the pre-test and post-test measurements of the groups. The differences between pre-test and post-test measurements in the two groups were examined with the independent t-test. $\mathrm{P}<0.05$ is considered statistically significant in the interpretation of our results. After eight weeks of training, both two groups' static balance and flexibility performances were significantly changed. But only the experiment group had significant improvement in the basketball skill test. The experiment group was also statistically changed in terms of all parameters compared to the control group. According to the results of this study it is possible to say that to improve basketball skills by improving balance and flexibility performance, eight weeks of step aerobic exercise is a useful training model for young basketball players.
\end{abstract}

Keywords: basketball, step aerobics, static balance, flexibility

\section{Introduction}

Basketball is one of the most popular sports in the world with a wide range of followers and practitioners. This popularity may because of including high scores, having fast and fantastic moves and being suitable for every age. It may also cause its continuing popularity in the media. Basketball has good visual aspects when performed by high level athletic players. Because of the rapidly changing positions between offence and defence, players must have high level motor performance especially combinations of sprints, flexibility, balance and strength to produce basketball skills such as jam shot, speed dribbling, stance slide, boxout and rebound, one to one offence and defence movements. Success in such combined movements with rapidly changing direction may have a strong relationship to balance and flexibility performance. Frequency of the variation in multidirectional movements was every two seconds during a game according to studies by Ben Abdelkerim et al.(2007) and Mclnnes et al. (1995). Previous studies summarised the strong relationship between athletic performance and balance and flexibility (Hrysomallis 2011, Gleim and McHugh 1997). Also many researchers reported the positive effects of step aerobic dance on flexibility and balance (Irez et al. 2014, Hallage et al. 2010, Anek et al. 2015, Anek and Bunyaratavej 2015, Federici et al. 2005). Previous studies focused on elderly groups or on women and non-specific sport branches. Does step aerobic dance practice have positive effects on basketball skills by improving static balance and flexibility performance? The effects of dance exercises on basketball skills and motor abilities are unclear and this study is the first on this topic. The aim of this study was to investigate the effects of eight weeks of step aerobic dance practice on static balance, flexibility and selected basketball skills in young basketball players.

\section{Method}

\subsection{Participants}

A total of 20 basketball players (average age $16.1 \pm 0.7$ years and average sporting age $4.1 \pm 0.7$ years) voluntarily joined 
the study. Players were members of the same basketball club. All participants were informed about the study and signed an informed consent form before the beginning of the study, which was approved by the Human Ethics Committee of Canakkale Onsekiz Mart University numbered 08-11-2012/173. The study was conducted in accordance with the Declaration of Helsinki, good clinical practices, and applicable laws and regulations.

Inclusion criteria were holding a basketball licence for a minimum of 2 years, without any muscle injury history and never having participated in step aerobic dance courses before. Exclusion criteria were lack of full participation in training activities, and history of previous muscle injury for a period of 8 weeks.

\subsection{Procedure}

Participants were randomly divided into two groups (experiment n:10 and control n:10). All participants attended basketball training 3 days per week but the experiment group also had step aerobic dance practices 2 days per week. Before and after the study static balance, flexibility and selected basketball techniques were evaluated.

Basketball training was performed for 90 minutes including 15 minutes of warm up exercises, 60 minutes basic technical exercises (ball handling, dribbling, passing, layup, shooting, one to one offense and defence) and 15 minutes of cool down exercises .

Step aerobic dance practices were performed on separate days to basketball training with a duration of 60 minutes and an authorized instructor. Dance practices consisted of three phases, warm-up (5 minutes dynamic stretching), step aerobic dance (50 minutes dance practice), and cooling down (5 minutes static stretching). The intensity of exercises was planned to have low to moderate intensity (50-60\% of maximum heart rate) to avoid fatigue effects. The exercise program was performed with music in a dance hall. Step aerobic dance practices included walking and step variations, knee bends, lunges (low impact aerobics), running, skipping and hopping (high impact) and combinations of these (low-high impact); this exercise was accompanied by controlled movement of the arms with eight repetitions as described by Çakmakçı et al.(2011). All participants completed the dance sessions without any injury.

\subsection{Data Collection}

Static balance, flexibility and selected basketball skills were evaluated before and after the study.

Flexibility was evaluated by using standard sit-and-reach test after three trials and best distance was recorded (ACSM 2000). Static balance was evaluated using the single-legged Flamingo balance test. The stance was held for one minute and the number of falls were counted and used as a measure of postural balance (Deforce et al. 2003).

Selected basketball skills were evaluated by using a racing circuit (Figure 1) which includes speed dribbling, passing, layup and shooting skills. Start and finish point were controlled via photocell by the players' own reactions. Best score was recorded after two trials.

The racing circuit includes 4 skill stations. Layup with both hands (A), slalom dribbling (B), passing (C), and stop jam shot (D). Instructions on the racing circuit were numbered as;

1: run and start photocell to get the ball under the basket the basket

2: dribbling with the left hand turn around the hurdle and make left hand layup, if not successful score under the basket

3: dribbling with the right hand turn around the hurdle and make right hand layup, if not successful score under

4: dribbling to station B and do slalom dribbling using both hands (each hurdle distance is 1 meter)

5: dribbling to station $\mathrm{C}$

6: do chest pass for the hit until the target is achieved

7: dribbling to the free throw line and stop for a jam shot. If it is successful run to the finish

8: if jamshot is unsuccessful, get the rebound and score under the basket and run to the finish to stop the photocell. 


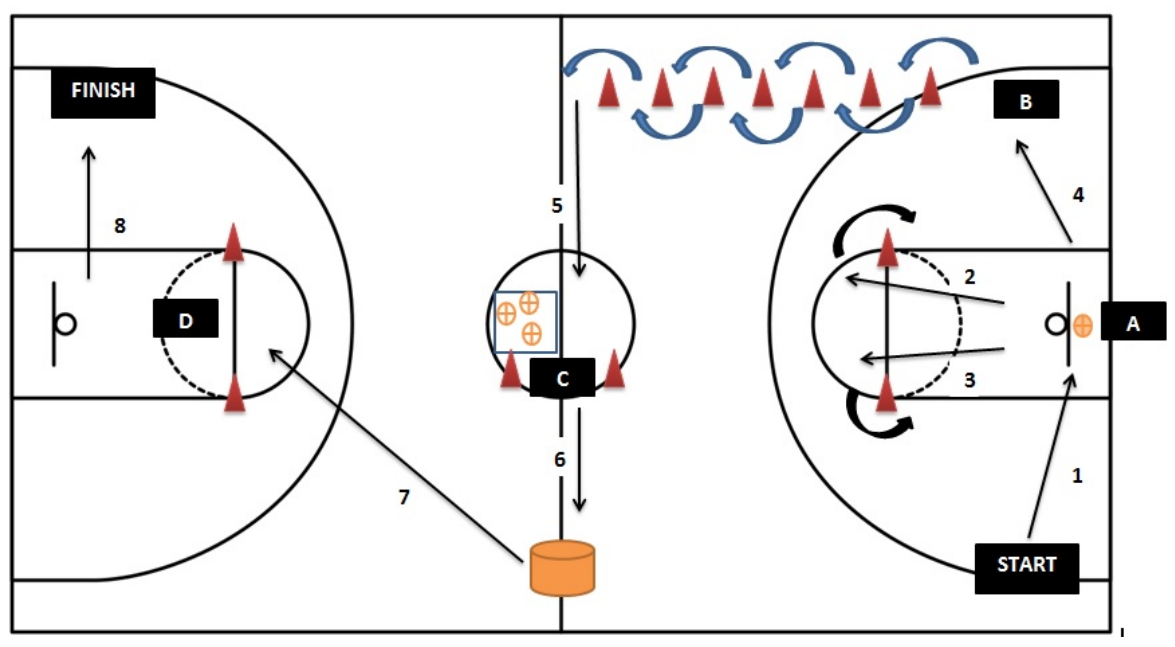

Figure 1. Basketball skill test racing circuit

\subsection{Statistical Analysis}

All data are expressed as mean \pm standard deviation (SD) and are analyzed using SPSS statistical program to calculate the mean and SD of the values collected. Repeated measures Anova was used to compare the pretest and posttest measurements of the groups. The differences between pretest and posttest measurements of the two groups were examined with the independent t-test. $\mathrm{P}<0.05$ is considered statistically significant in the interpretation of our results.

\section{Results}

Table 1. Demographic characteristics of participants (mean \pm standard deviation)

\begin{tabular}{lccc}
\hline Groups & Age (year) & Body height $(\mathrm{cm})$ & Body weight $(\mathrm{kg})$ \\
\hline Experiment (n:10) & $16.1 \pm 0.8$ & $177.2 \pm 5.3$ & $70.8 \pm 8.8$ \\
Control (n:10) & $16.1 \pm 0.8$ & $173.1 \pm 3.1$ & $71.5 \pm 5.3$ \\
Total (n:20) & $16.1 \pm 0.7$ & $175.1 \pm 4.7$ & $71.1 \pm 7.1$ \\
\hline
\end{tabular}

Findings about demographic characteristics of the groups (mean and standard deviation) are shown in Table 1. According to the table a total of 20 participants participated in the study and their average ages, body height and body weight were $16.1 \pm 0.7$ years, $175.1 \pm 4.7 \mathrm{~cm}$, and $71.1 \pm 7.1 \mathrm{~kg}$ respectively. There were no significant differences between the groups in terms of demographic variables.

Table 2. Pre-test and post test performances of groups (mean \pm standard deviation)

\begin{tabular}{lcccc}
\hline \multirow{2}{*}{ Variables } & \multicolumn{3}{c}{ Groups } \\
\cline { 2 - 5 } & \multicolumn{3}{c}{ Experiment } & \multicolumn{2}{c}{ Control } \\
\cline { 2 - 5 } & Pre-test & Post-test & Pre-test & Post-test \\
\hline Static balance (falls) & $3.6 \pm 0.8$ & $1.7 \pm 0.4^{*}$ & $4.3 \pm 0.9$ & $3.5 \pm 0.5^{*}$ \\
Flexibility (cm) & $19.1 \pm 4.8$ & $23.9 \pm 4.7^{*}$ & $19.7 \pm 2.9$ & $20.9 \pm 2.6^{*}$ \\
Basketball skill (sec) & $51.1 \pm 6.1$ & $42.7 \pm 5.6^{*}$ & $49.7 \pm 5.7$ & $49.8 \pm 4.6$ \\
\hline
\end{tabular}

*: significant differences at $p<0.05$ level between pre-test and post-test

Findings related to mean values of pre-test and post-test performance and statistical analysis results of pre-test and post-test differences in the variables are shown in Table 2. After eight weeks of training, static balance, flexibility and basketball skill test performances of the experiment group were positively changed. Paired t-test analysis proved that this change was statistically significant (t: 6.042 p:0.001, t:-21.000 p:0.001, t:11.353 p:0.001 respectively). After the trial period static balance and flexibility performance of the control group were positively changed. Paired t-test analysis proved that this change was statistically significant (t:2.753 p:0.022, t:-9.000 p:0.001, respectively). But basketball skill test scores did not change. 
Table 3. Pre-test and post-test differences between the groups (mean \pm standard deviation)

\begin{tabular}{lcc}
\hline Variables & \multicolumn{2}{c}{ Groups } \\
\cline { 2 - 3 } & Experiment & Control \\
\hline Static balance (falls) & $-1.9 \pm 0.9^{*}$ & $-0.8 \pm 0.9$ \\
Flexibility (cm) & $4.9 \pm 0.7^{*}$ & $1.2 \pm 0.4$ \\
Basketball skill (sec) & $-8.3 \pm 2.3^{*}$ & $0.1 \pm 2.9$ \\
\hline
\end{tabular}

*: significant differences at $p<0.05$ level between two groups

Pre-test and post-test differences between the groups (mean \pm standard deviation) and statistical analysis of the differences are shown in Table 3. According to the table important differences were found in the static balance, flexibility and basketball skill performance of the groups. T-test analysis proved that differences in the pre-test and post-test of static balance, flexibility and basketball skill test performance of the groups were significantly different (t:2.559 p:0.01, t:-13.768 p: 0.001, t:7.016 p:0.001, respectively). The experiment group was statistically changed in terms of all parameters compared to the control group.

\section{Discussion}

The aim of this study was to investigate the effects of eight weeks of step aerobic dance exercises on static balance, flexibility and selected basketball skills in young basketball players. After the eight weeks of training the step aerobic and control group had significant improvements in flexibility and static balance performance but only the experiment group had significant improvements in basketball skill performance. Also when the two groups are compared, analysis proved that the experiment group had significant improvements in all parameters compared to the control group. Previous studies noted that after various periods of step aerobics participants had significant improvements in physiological and motor performance parameters. For example, Nikić and Milenkovic (2013) noted that step aerobic practice significantly improved motor skills and body composition of young girls. Hale and Raglin (2002) found that step aerobic practice significantly reduced state anxiety levels in adults. Arslan (2011) reported that participating in regular step aerobic exercises significantly affected loss of body weight in obese women. Kraemer et al. (2000) found that step aerobic exercises are an effective exercise type to improve physical fitness and body composition in healthy women. A similar report published by Gezer and Çakmakçı (2011) found that step aerobic practice had positive effects on body composition and quality of life. Işler et al. (2001) reported that step aerobic exercise is an effective training mode for lipid and lipoprotein profiles of female college students. Demirci (2013) also supported the literature by finding step aerobic exercises significantly decreased the cholesterol level of university students. Kurt et al. (2010) noted that step aerobic training provided significant improvements in flexibility, anaerobic power, aerobic capacity, leg strength, right and left hand grip strengths of middle aged women. Hallage et al. (2010) found that strength of the upper and lower body, dynamic balance and agility, flexibility and cardiorespiratory fitness were significantly positively affected after step aerobic exercises in adults. Similar findings were reported by Mori et al. (2006) who found that a bench step exercise program effectively improved aerobic capacity, lower extremity power and static balance ability in the elderly.

The effectiveness of step aerobic dance has been reported by many researchers. But the benefits of this type of exercise for basketball skills have not been investigated yet. This study is the first and results of this study showed that step aerobic exercises provided significant improvements in basketball skills of young basketball players by improving their balance and flexibility performance. Previous studies analysed the effectiveness of various forms of loading on basketball skills. For example, Inovero and Pagaduan (2015) reported that passing skill was significantly improved after six weeks of strength training in college basketball players. Woolstenhulme et al. (2004) noticed that shooting skills of collegiate female basketball players was not affected after four weeks of strength training. Similar findings were reported by Shoenfelt (1991) who found that free throw shooting skill was not affected immediately after strength training. Bogdanis et al. (2007) performed four weeks of mixed strength and basketball training to investigate the effects on basketball skills and found that mixed training periods had similar effects as basketball training alone on basketball skills.

A recent study showed that findings on the effectiveness of step aerobic exercises on basketball skill are new. There are more study findings needed to discuss these effects. But it is possible to say that because of the benefits of step aerobics on physiological and motor variables, these findings were expected. One limitation of this study was that the effects of muscle strength on basketball skills were not tested. Future studies are planned on that topic. According to results of this study it is possible to say that to improve basketball skills by improving balance and flexibility performance, eight weeks of step aerobic exercise is a useful training model for young basketball players. 


\section{Acknowledgement}

I would like to thank the players from Çanakkale Onsekiz Mart University Sports Club for voluntarily participating in the study. I would also like thank Özlem Köybaşı to help in performing the step aerobic exercises.

\section{References}

American College of Sports Medicine (ACSM) (2000). Guidelines for exercise testing and prescription. $6^{\text {th }}$ ed. Baltimore, MD: Lippincott Williams \& Wilkins

Anek, A., \& Unyaratavej, N. (2015). Effects of circuit aerobic step exercise program on musculoskeletal for prevention of falling and enhancement of postural balance in postmenopausal women. J The Med. Assoc. Thai, 98(8), 88-94 http://www.ncbi.nlm.nih.gov/pubmed/26529821

Anek, A., Kanungsukasem, V., \& Bunyaratavej, N. (2015). Effects of aerobic step combined with resistance training on biochemical bone markers, health-related physical fitness and balance in working women. J. The Med. Assoc. Thai, 98(8), 42-51. http://www.ncbi.nlm.nih.gov/pubmed/26529814

Arslan, F. (2011). Effects of a step-aerobic dance exercise programme on body composition. Int. Sport Med J, 12(4), 160-168 URL: http://www.ismj.com

Ben, A. N., El, F. S., \& El, A. J. (2007). Time-motion analysis and physiological data of elite under-19-year-old basketball players during competition. Br J Sports Me, 41(2), 69-75. http://dx.doi.org/10.1136/bjsm.2006.032318

Bogdanis, G. C., Ziagos, V., Anastasiadis, M., \& Maridaki, M. (2007). Effects of two different short-term training programs on the physical and technical abilities of adolescent basketball players. J Sci.Med. in Sport, 10,79-88. http://dx.doi.org/10.1016/j.jsams.2006.05.007

Çakmakçı, E., Arslan, F., Taşkın, H., \& Çakmakçı, O. (2011). The Effects of Aerobic Dance Exercise on Body Composition Changes Associated with Weight Change in Sedentary Women. Turk J Sport Exe, 13(3), 298 -304.

Deforche, B., Lefevre, J., De, B. I., Hills, A. P., Duquet, W., \& Bouckaert, J. (2003). Physical fitness and physical activity in obese and nonobese Flemish youth. Obes. Res., 11, 434-441. http://dx.doi.org/10.1038/oby.2003.59

Demirci, N. (2013). The effect of 14 week regular aerobic-step exercises on female university students' cholesterol levels. Sci. Mov. And Health, 13(2), 506-511. http://www.analefefs.ro/anale-fefs/2013/s1/pe-autori/66.pdf

Federici, A., Bellagamba, S., \& Rocchi, M. B. L. (2005). Does dance-based training improve balance in adult and young old subjects? A pilot randomized controlled trial. Aging Clin.and Exp. Res., 17, 385-389. http://dx.doi.org/10.1007/BF03324627

Gezer, E., Çakmakçı, E. (2011). The effect of 8 weeks step-aerobic exercise program on body composition and quality of life of sedantery women. Sci. Mov. And Health, 11(1), 97-101.

http:/connection.ebscohost.com/c/articles/60304249/effect-8-weeks-step-aerobic-exercise-program-body-composit ion-quality-life-sedantery-women

Gleim, G. W., \& McHugh, M. P. (1997). Flexibility and its effects on sports injury and performance. Sports Med, 2(5), 289-299. http://dx.doi.org/10.2165/00007256-199724050-00001

Hale, B. S., \& Raglin, J. S. (2002). State anxiety responses to acute resistance training and step aerobic exercise across 8-weeks of training. J Sport Med. and Phy. Fit, 42, 108-112. http://www.ncbi.nlm.nih.gov/pubmed/11832884

Hallage, T., Krause, M. P., Haile, L., Miculis, C. P., Nagle, E. F., Reis, R. S., \& Da Silva, S. G. (2010). The effects of 12 weeks of step aerobics trainıng on functional fitness of elderly women. J St.and Cond. Res., 24(8), 2261-2264. http://dx.doi.org/10.1519/JSC.0b013e3181ddacc6

Hrysomallis, C. (2011). Balance ability and athletic performance. Sports Med, 41(3), 221-232. http://dx.doi.org/10.2165/11538560-000000000-00000

Inovero, J. G., \& Pagaduan, J. C. (2015). Effects of a six-week strength trainıng and upper body plyometrics in male college basketball physical education students. Sport Spa. 12(1), 11-16. http://www.sportspa.com.ba/images/june2015/Article-02-june-2015.pdf

Irez, G. B., Özcan, S. Ö., Yıldırım, S., \& Ceylan, H. I. (2014). Aerobıc dance or step dance: which exercise can increase balance, flexibility and muscle strength of university students? SSTB Int.Ref. Acd. J Sports, Health \& Med. Sci., 13(4), 143-163.

http:/connection.ebscohost.com/c/articles/98782823/aerobic-dance-step-dance-which-exercise-can-increase-balan ce-flexibility-muscle-strength-university-students

Işler, A. K., Kosar, S. N., \& Korkusuz, F. (2001). Effects of step aerobics and aerobic dancing on serum lipids and 
lipoproteins. J Sports Med. Phy. Fit, 41(3), 380-385. http://www.ncbi.nlm.nih.gov/pubmed/11533570

Kraemer, W. J., Keunıng, M, Ratamess, N. A., Volek, J. S., Mccormick, M., Bush, M. J., N,iindl, B. C., Gordon, S. E., Mazzettı, S. A., Newton, R. U., Gómez, A. L., Wıckham, R. B., Rubın, M. R., \& Häkkınen, K. (2010). Resistance training combined with bench-step aerobics enhances women's health profile. Med. \& Sci. in Sports \& Ex, 259-269. http://www.ncbi.nlm.nih.gov/pubmed/11224816

Kurt, S., Hazar, S., Ibiş, S., Albay, B., \& Kurt, Y. (2010). Evaluation of the effects of eight-week step-aerobic exercise program on some fitness parameters at middle aged sedentary women. Int. J Human Sci, 7(1), 665-674. https://www.j-humansciences.com/ojs/index.php/IJHS/article/view/1142

Mclnnes, S. E., Carlson, J. S., Jones, C. J., \& McKenna, M. J. (1995). The physiological load imposed on basketball players during competition. J Sports Sci., 13, 387-397. http://dx.doi.org/10.1080/02640419508732254

Mori, Y., Ayabe, M., Yahiro, T., Tobina, T., Kiyonaga, A., Shindo, M., Yamada, T., \& Tanaka, H. (2006). The effects of home-based bench step exercise on aerobic capacity, lower extremity power and static balance in older adults. Int. J Sport and Health Sci., 4, 570-576. http://dx.doi.org/10.5432/ijshs.4.570

Nikić, N., \& Milenković, D. (2013), Efficiency of step aerobıc program in younger Women. Act. Med. Median., 52(3), 25-34. http://dx.doi.org/10.5633/amm.2013.0304

Shoenfelt, E. L. (1991). Immediate effect of weight training as compared to aerobic exercise on free-throw shooting in collegiate basketball players. Perceptual and Motor Skills, 73, 367-370.

http://dx.doi.org/10.2466/pms.1991.73.2.367

Woolstenhulme, M. T., Bailey, B. K., \& Allsen, P. E. (2004). Vertıcal jump, anaerobıc power, and shootıng accuracy are not altered 6 hours after strength trainıng in collegiate women basketball players. J Strength \& Cond. Res, 18(3), 422-425. http://dx.doi.org/10.1519/13463.1 